\title{
Attentional functions in speech fluency disorders
}

\author{
Ragnhild Rekve Heitmann ${ }^{1}$, Arve Asbjørnsen ${ }^{2}$ and Turid Helland ${ }^{1}$ \\ From the ${ }^{1}$ Centre for Logopedics, Eikelund Resource Centre, Bergen, Norway and ${ }^{2}$ Department of Psychosocial \\ Sciences, University of Bergen, Norway
}

Received 6 November 2003. Accepted 28 May 2004.

Logoped Phoniatr Vocol 2004; 29: 119-127

This study focused on attentional functions in fluency disorders. Nine persons who stuttered, eight persons who cluttered, and nine fluent controls, executed a set of attention tasks while psychophysiological indices of activation (heart rate variability and skin conductance) were recorded. The results indicated that the stutter group had a significantly longer response time on the Posner Test of Covert Attention Shifts than the other two groups, and the effect was most obvious when the target appeared in the right visual field. There were no significant differences between groups in the physiological activation as measured by heart rate, skin conductance and heart rate variability. The present results support the hypotheses that stuttering may be associated with impaired skills to focus attention, while cluttering did not seem to be associated with impaired focused attentional skills. However, the sample available within the study period was limited, and due to small samples care should be taken before making firm conclusions.

Key words: attention, cluttering, heart rate variability, skin conductance, stuttering.

Ragnhild Rekve Heitmann, Centre for Logopedics, Eikelund Resource Centre, PB 6039, Postterminalen, N-5892 Bergen, Norway. E-mail: ragnhild.r.heitmann@statped.no

\section{INTRODUCTION}

\section{Fluency disorders}

The most common fluency disorders are stuttering and cluttering. There has not as yet been any agreement about the aetiology of stuttering, but different definitions have reflected the different viewpoints of researchers. Stuttering has been described as an exceptionally complex phenomenon linked to genetics (2) (Yari, Ambrose \& Cox, 1996), neurology (De Nil et al., 2000) (25), physiology (30) (McFarlane \& Prins, 1978) (58), and psychological factors (7, 8, 12). A prevalence of less than $1 \%$ is often quoted (45). Cluttering is estimated to affect about $1.5 \%$ of the population (3).

\section{Stuttering}

Three aspects are commonly included in definitions of stuttering: language behaviour $(45,46,57)$, emotional functions $(6,7,37,48)$, and communicative skills (6).

The language behaviour aspect is observable during speech. Speech repetitions, sound prolongations, and articulatory blocks characterize stuttering $(24,49,57)$,

Electroencephalographic and functional imaging studies of the brain indicate deviant activation patterns in stutterers as compared to non-stutterers
(Braun et al., 1997; De Nil et al., 1995) (35, 36, 24). While non-stutterers tend to activate predominantly left hemispheric brain structures when speaking or reading, stutterers show less left hemispheric activation and more activity in the same areas of the right hemisphere (Braun et al., 1996; De Nil et al., 1995) (24). The emotional aspect of stuttering implies that the person is emotionally influenced, in varying degrees, by the stuttering. Measures of physiological arousal such as heart rate variability and skin conductance have been used to assess whether people who stutter are more anxious than those who do not stutter. Cognitive stress combined with demands on rapid speech resulted in more speech interruptions and significantly higher levels of arousal in persons who stutter than in persons who do not stutter $(10,43)$. Other researchers have not found any psychophysiological differences between people who stutter and fluent speakers $(32,59)$.

The communicative aspect emphasizes that stuttering occurs only in communication with others and may thus create interference $(6,23,12)$. Each of these three aspects can only partially describe the nature of stuttering.

In the present study, stuttering is defined as a disorder of fluency of speech, including repetitions, 
prolongations and blocks, accompanied by increased muscular tension, which may cause a reaction in the subject, leading to disrupted communication $(24,45)$.

\section{Cluttering}

Cluttering has typically been described as impaired speech, characterized by rapid or irregular speech rate, omissions and inversions of sounds, syllables and words (29), or as a disorder of fluency, timing and articulation $(38,39)$. Definitions of cluttering describe both articulatory and linguistic aspects as major characteristics (St. Louis et al., 1985) (18). Cluttering is probably due to a neurological dysfunction (16).

Cluttering is also described as a language disorder $(18,61)$. Cluttering is usually not accompanied by fright or fear, or identification of problems with specific words or sounds. A person who clutters does not perceive the speech as deviant (61). The emotional aspect will usually be different for a person who clutters compared with a person who stutters. Whereas a person who clutters is unconcerned about his own speech, a person who stutters would be self-conscious and worried about what others would think of him (61). However, these assumptions are based on clinical experience, not on systematic empirical studies.

The two dysfluency groups differ when analysing the communicative aspect. A person who clutters manages communication skills better under pressure than in a relaxed environment, and is more fluent after an interruption than a person with stuttering (61). Pragmatic perspectives on cluttering indicate that persons with cluttering frequently manifest pragmatic errors and communication failures, compared to normal speakers (54). This may be associated with poor linguistic skills or inattention during the planning of a speech action (61).

Cluttering has been a neglected area in the field of speech and language research (Meyers, 1992). This may be due to its multifaceted and complex nature (Meyers \& St. Louis, 1992). Cluttering occurs as a single symptom or combined with stuttering. Two cluttering subgroups have been identified (54): classical cluttering, where the motor aspect in speech is the primary deficit, and cluttering as a part of a syndrome.

This supports the hypothesis that cluttering is due to an organic anomaly in the central nervous system $(45,61)$.

In the present study, cluttering was defined as a disorder of fluency, timing, articulation and language. Communication failures associated with impaired attention and poor linguistic skills are also included in the definition of cluttering in this study. For cluttering assessment the 'Cluttering Symptoms Summary Checklist' (Daly \& Burnett, 1996) was used. The checklist is an assessment tool containing items researchers believe to be indicative of cluttering (Daly, 1996; St. Louis, 1992) (61), but it is not intended to be an instrument used for research purposes (Daly, 1996).

\section{Attention}

Attention is a complex process involving different functions and areas in the brain. Mirsky (33) proposed a model for attention involving five distinct functions: the capacity to focus/execute, to encode, to shift, to sustain and to stabilize attention. The focus/executive function involves the ability to select relevant stimuli from a broad array of stimuli and carry out the task in an effective way. The shift functions involve the ability to change focus in a flexible way. Sustained attention is defined as vigilance or the capacity to maintain focus over time. The focus/executive function is mainly associated with the frontal regions of the brain, the superior-parietal and temporal areas, as well as parts of the basal ganglia. Encoding is associated with the hippocampus and the amygdala. The ability to shift attention relates to structures of the dorso-lateral prefrontal cortex, while the ability to sustain attention is associated with functions in the thalamus and the reticular substance. This organization of the 'attention system' implies both specialization and interaction. In the present study three of these functions were assessed: the sustain function, the shift function and the focus/executive function.

Attention is associated with physiological activation, and activation can be studied by looking at differences in heart activity and skin conductance during rest and under cognitive demand (27). Also, physiological activation may have implications for attention (27). Brief changes in heart rate typically follow significant events that involve shifts of attention. Focusing of attention usually involves mental effort, and the allocation of 'executive' processing increases blood flow for processing the attended events (27, p. 228). Attention at a higher cognitive level involves the control of behaviour and actions of judgement, of the ability to use feedback to alter strategies, and self-regulation (56).

Studies have been carried out around single cognitive functions in fluency disorders $(5,10,3460)$, but so far no one has presented data from a diversity of attention-tests, controlling for physiological activity with persons with fluency disorder.

Based on the stutterers' awareness of others' reactions to their speech it may be expected that stutterers have a better ability to shift attention than clutterers (cp. 45, 61). However, a better ability to sustain attention may be seen in clutterers compared to 
stutterers based on a general observation that they cope better under pressure and are unconcerned with their speech problems (cp. Meyers \& St. Louis, 1992) (61).

The hypotheses in the present study were: 1) subjects who stutter have a better ability to shift attention than to focus and sustain attention, compared to subjects who clutter and a control group; 2) subjects who clutter have a better ability to focus and sustain attention than to shift attention, compared to persons who stutter and a control group; 3) based on the assumption that speech would provide more discomfort to a person who stutters than to a person who clutters, we expect to see differences in activation as measured by heart rate variability between the two groups with fluency disorders; 4) attentional efficacy was expected to be explained by variations in activation.

\section{METHOD}

\section{Subjects}

The dysfluency group consisted of 17 subjects (aged 9-17 years), referred by the local psychology agencies for assessment and counselling, and further referred to a regional logopedic clinic. Stutterers were assessed by the differential-diagnostic model of Ainsworth 1977, and the clutterers were assessed by the 'Cluttering Symptoms Summary Checklist' (Daly, 1996). This made two subgroups: 9 stutterers (ST) (aged 11-15, mean age 13.41 (SD 1.76); 6 males and 3 females), and 8 clutterers (CL) (aged 9-17, mean age 13.88 (SD 2.88); 6 males and 2 females). The control group (Con) consisted of 9 subjects (aged 11-16, mean age 13.64 (SD 1.90); 6 males and 3 females) who were matched in age and gender with the dysfluency groups. Criteria for inclusion were: normal intellectual abilities as defined by full scale IQ (FIQ) $>70$, with either verbal IQ (VIQ) $>80$ or performance IQ (PIQ) $>80 \mathrm{cp}$. (21) no records of need for special needs education; no neurological impairments; normal visual and auditory functions and Norwegian as their first language. There were significant differences between the cluttering group and the control group according to VIQ ( $p<$ $0.05)$, PIQ $(p<0.12)$ and FIQ $(p<0.006)$, where the cluttering group showed the lowest scores. Descriptive data are shown in Table 1.

\section{Experimental tests}

The following tests of attention were applied:

The Posner Test of Covert Attention Shift (44) consists of the sub-tests Endopos, and Exopos. Endopos has been described as measuring controlled attention, while Exopos measures automatic and stimuli-driven shifts of attention. The test was administered on a computer screen showing a central location cross and two peripheral boxes. Throughout the trials, the subjects had to fixate the eyes on the central location. The target, to which the subjects were to respond, appeared after an interval of varied time. The subjects were instructed to press a key on the keyboard when a cue appeared. Two types of trials were given: valid trials in which the cue correctly predicted the location of the subsequent target, and invalid trials, in which the cue incorrectly predicted the location of the subsequent target. The dependent variable was mean response time in milliseconds.

Conners Continuous Performance Test (CPT), (11) was used for measures of sustained attention. The subjects were instructed to press a key on the keyboard when a letter was presented on the screen. The dependent variables were the number of times the subject correctly responded to the stipulated letter $(\mathrm{K})$ stimulus on the computer screen (correct), the number of missed stimuli (omissions), the number of responses to other letters (commissions) and mean response time (ms).

The Dichotic Listening Test (DL, DLCV-108), (28) is an auditory test commonly applied to assess language lateralization, sustained attention and the ability to shift attention. The subjects were given tasks with two conditions: 1) non-forced attention, where the task of the subject was to repeat what he or she heard best; 2) forced attention where attention was

Table 1. Descriptive data for the stuttering group (ST), the cluttering group (CL), and the control group (con)

\begin{tabular}{lllllllr}
\hline & $N=26$ & Age & $\begin{array}{l}\text { Gender } \\
\text { male/female }\end{array}$ & $\begin{array}{l}\text { Hand- preference: } \\
\text { right/left }\end{array}$ & $\begin{array}{l}\text { VIQ WISC-R } \\
\text { Mean (SD) }\end{array}$ & $\begin{array}{l}\text { PIQ WISC-R } \\
\text { Mean (SD) }\end{array}$ & $\begin{array}{l}\text { TIQ WISC-R } \\
\text { Mean (SD) }\end{array}$ \\
\hline ST & 9 & $13.41(1.76)$ & $6 / 3$ & $8 / 1$ & $108.66(16.49)$ & $102.11(14.41)$ & $106.55(12.75)$ \\
CL & 8 & $13.88(2.88)$ & $6 / 2$ & $8 / 0$ & $103.87(18.53)$ & $93.37(10.04)$ & $98.75(11.81)$ \\
Con & 9 & $13.64(1.90)$ & $6 / 3$ & $8 / 1$ & $120.00(12.74)$ & $108.88(10.24)$ & $116.11(11.36)$ \\
\hline
\end{tabular}

Note: WISC-R = Wecheler Intelligence Scale for Children-Revised; VIQ = Verbal IQ; PIQ = Performance IQ; FIQ =Full IQ. 
directed to the right ear (FR) or to the left ear (FL), balanced between subjects. The test was administered and scored according to the instructions given in (28). Compared to the former procedures, DLCV measures auditory attention as opposed to visual attention.

The Stroop Color Word Test (SCWT), (22, 53), Norwegian version Hugdahl, no date was used to measure the shift function. The test consists of 48 items for each of the three tasks of 'color' naming (C), 'word' reading (W) and 'color/word' naming (CW), presented in fixed order, and analysed separately for speed (s) and correct responses (cr).

The Wisconsin Card Sorting Test (WCST), (4), WCST-CV2, (26) was used to assess the focus/execute function. The following six variables were examined in this study: total numbers of 1) cards administered (TA), 2) errors (TE), 3) perseverative responses (PR), 4) categories completed (CC), 5) perseverative errors (PE), and 6) non-perseverative errors (NPE) (see Table 2).

All tests are widely used clinically and in international neuropsychological research.

Heart rate (HR), heart rate variability (HRV) and skin conductance level (SCL) were measured with the Ambulatory Monitoring System (AMS36; Vrije Universität, Department of Psychophysiology). Psychophysiological activation was measured during rest and during attentional testing.
HR was recorded as beats per minute, measured as the interval in milliseconds between each successive Rwave (the R-R interval). SCL was recorded as level of conductance in micro-Siemens $(\mu \mathrm{S})$. In addition, the root mean of squared successive differences (MSSD) between each heartbeat was calculated and used as a measure of HRV see e.g. (55).

\section{Design and statistical analysis}

Data from the tests were analysed by using descriptive statistics and analyses of variance (ANOVA). Initial analyses were based upon the raw-scores from the different tests in a Group (3: ST, CL, Con) by Task mixed design. The alpha level was set to $p<0.05$. Significant main effects and interactions were followed up with Fisher's Least Significant Difference (LSD).

\section{RESULTS}

\section{Cognitive tests}

WISC-R yielded significant differences between the cluttering group and the control group both on VIQ, PIQ and TIQ.

Analyses of variance of the performance on DL, SCWT, WCST and CPT yielded no significant differences between the groups. However, there was a

Table 2. Mean (SD) for the stuttering, cluttering and control groups of the Dichotic Listening Test, the Stroop Color Word Test and the Wisconsin Card Sorting Test

\begin{tabular}{lcrr}
\hline & $\begin{array}{l}\text { Control, } N=9 \\
\text { Mean (SD) }\end{array}$ & $\begin{array}{l}\text { Stuttering, } N=9 \\
\text { Mean (SD) }\end{array}$ & $\begin{array}{c}\text { Cluttering, } N=8 \\
\text { Mean (SD) }\end{array}$ \\
\hline DL NF RE & $12.00(3.39)$ & $12.55(2.92)$ & $13.37(4.13)$ \\
DL NF LE & $10.66(1.93)$ & $10.00(3.31)$ & $9.12(2.41)$ \\
DL FR RE & $17.88(3.65)$ & $17.11(4.45)$ & $16.75(4.65)$ \\
DL FR LE & $8.22(2.63)$ & $8.88(3.65)$ & $7.37(2.26)$ \\
DL FL RE & $14.00(4.27)$ & $13.66(4.35)$ & $13.25(3.32)$ \\
DL FL LE & $11.88(5.46)$ & $11.44(4.21)$ & $10.12(2.47)$ \\
DL zASI & $0.94(1.61)$ & $0.82(1.15)$ & $0.86(1.23)$ \\
DL zLAMBDA & $0.24(0.71)$ & $0.54(0.98)$ & $0.83(1.05)$ \\
Stroop C-RT & $35.11(9.59)$ & $47.88(27.55)$ & $37.12(14.59)$ \\
Stroop W-RT & $19.88(3.10)$ & $75.00(2.87)$ & $30.00(23.30)$ \\
Stroop CW-RT & $61.55(19.11)$ & $59.91(21.04)$ & $64.62(16.80)$ \\
Stroop INT-RT & $49.05(18.19)$ & $30.66(12.83)$ & $48.46(11.60)$ \\
WCST TE & $29.88(24.52)$ & $11.88(6.27)$ & $41.25(20.31)$ \\
WCST Persev. Errors & $11.55(7.50)$ & $18.77(9.58)$ & $18.12(11.33)$ \\
WCST NE & $18.33(17.24)$ & $5.55(0.72)$ & $23.12(11.33)$ \\
WCST CC & $5.11(1.76)$ & $1.00(1.50)$ & $5.12(1.45)$ \\
WCST FMS & $0.77(0.66)$ & & $0.87(1.24)$ \\
\hline
\end{tabular}

Note: $\mathrm{DL}=$ dichotic listening; $\mathrm{NF}=$ non-forced; $\mathrm{FR}=$ forced right; $\mathrm{FL}=$ forced left; $\mathrm{RE}=$ right ear; LE =left ear; DL $z A S I=$ standardized score of Attentional Shift Index; $z$ LAMBDA $=$ standardized LAMBDA score; Stroop $=$ Stroop Colour-Word Test; $\mathrm{C}=$ colour-naming task; $\mathrm{W}=$ colour-word reading; $\mathrm{CW}=$ colour/word; $\mathrm{RT}=$ response time in seconds; WCST $=$ Wisconsin Card Sorting Test; TE $=$ total errors; NE $=$ non-perseverative errors; INT $=$ interference scores; $\mathrm{FMS}=$ failure to maintain set; $\mathrm{CC}=$ categories completed. 
Table 3. Mean (SD) of the Conners Continuous Performance Test (CPT)

\begin{tabular}{lccc}
\hline CPT & $\begin{array}{l}\text { Control, } N=9 \\
\text { Mean (SD) }\end{array}$ & $\begin{array}{l}\text { Stuttering, } N=9 \\
\text { Mean (SD) }\end{array}$ & $\begin{array}{l}\text { Cluttering, } N=8 \\
\text { Mean (SD) }\end{array}$ \\
\hline CPT Target hits 1.t & $36.00(17.84)$ & $48.44(11.94)$ & $47.50(12.45)$ \\
CPT Target hits 6.t & $33.00(16.18)$ & $47.11(11.28)$ & $46.25(11.85)$ \\
CPT Total omissions 1.t. & $2.00(1.87)$ & $1.55(1.94)$ & $2.00(1.85)$ \\
CPT Total omissions 6.t. & $5.00(7.41)$ & $2.8(3.05)$ & $3.25(3.45)$ \\
CPT Non-target rejections 1.t. & $1.22(1.20)$ & $1.11(0.78)$ & $1.75(1.16)$ \\
CPT Non-target rejections 6.t. & $1.33(1.22)$ & $4.44(1.59)$ & $3.87(1.12)$ \\
CPT Non-target commission 1.t. & $3.00(1.73)$ & $4.33(1.87)$ & $3.62(1.50)$ \\
CPT Non-target commission 6.t. & $2.88(1.90)$ & $312.33(38.53)$ & $308.37(41.65)$ \\
CPT Overall reaction time. 1.t. & $292.22(41.80)$ & $349.66(91.32)$ & $368.25(70.19)$ \\
CPT Overall reaction time 6.t. & $381.44(58.68)$ & & \\
\hline
\end{tabular}

Note: $1 . t=$ Trial number $1 ; 6 . t=$ Trial number 6.

tendency to higher error rate in the cluttering group on the WCST (see Tables 2 and 3). These tendencies should be further exploited in a larger sample.

\section{Posner Test of Covert Attention Shift}

Figure 1 depicts the performance on the two subtests of the Posner Test of Covert Attention Shift separately for the three groups. The performance on the tests was analysed by a four-way ANOVA with Group (3: Con,
ST, CL) $\times$ Test (2: Exopos, Endopos) $\times$ Cue (3: Valid, Invalid, No Cue) $\times$ VF (Visual Field) (2: Right Field, Left Field). The analysis yielded a significant Group by Test interaction, $\mathrm{F}(4,46)=13.73, p<0.001$. Fisher's LSD follow-up test showed that this was due to the stutterers having longer response time in Endopos $(p<0.008)$ and Exopos $(p<0.01)$ compared with clutterers $(p<0.008$ and $p<0.01$, respectively). The controls showed shorter response time in Endopos than the two other groups $(p<0.05)$ There was also a

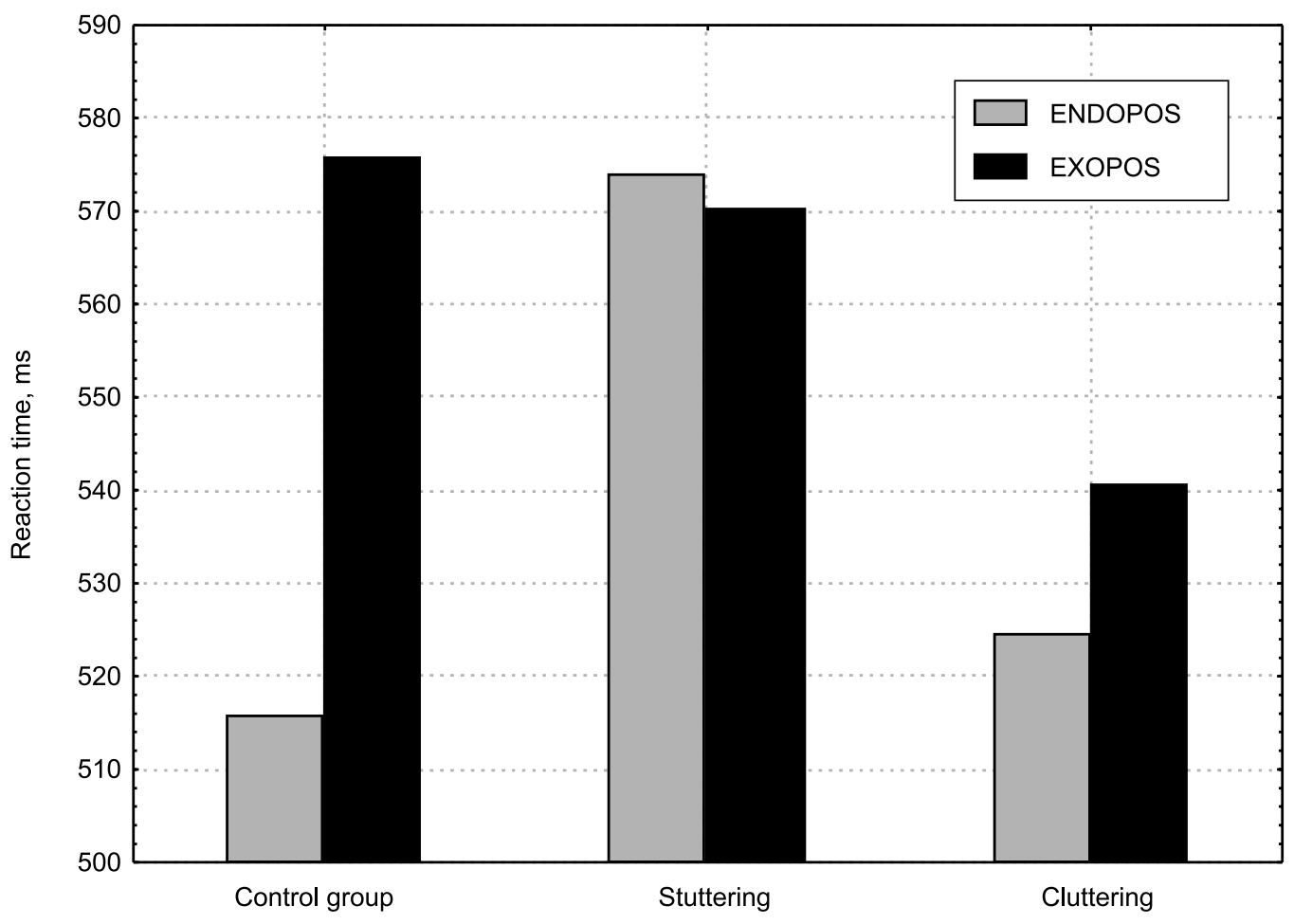

Fig. 1. Response time in ms on the Posner tests Exopos and Endopos separated for the control group, the stuttering group, and the cluttering groups 

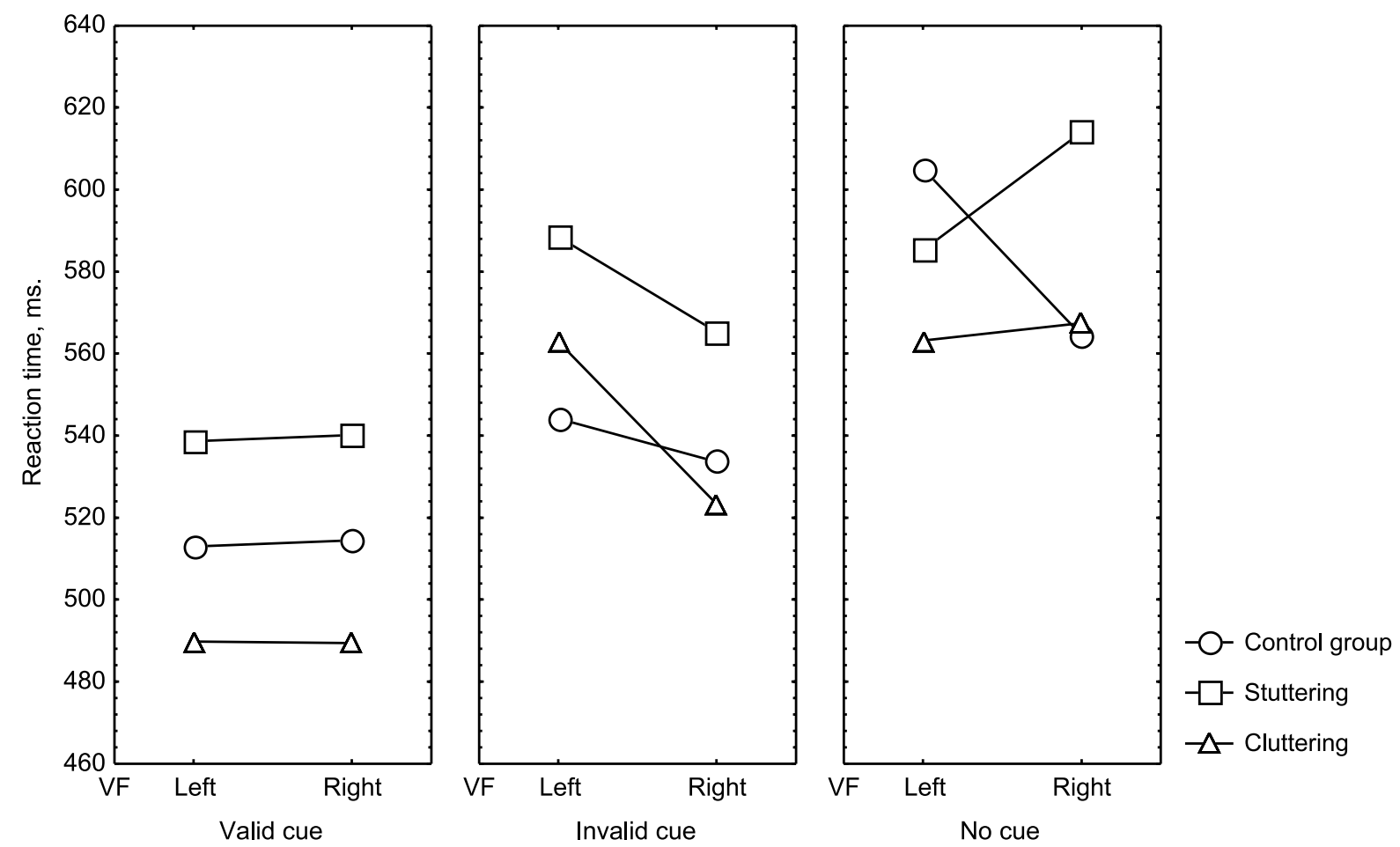

Fig. 2. Response time in ms on the Posner test of covert attention shift. Response time is depicted separately for groups, cues and visual field

significant Group by Cue by VF interaction, $\mathrm{F}(4$, $46)=2.65, p<0.04$. Follow-up with LSD test showed that all groups used shorter response time on Valid versus No cue $(p<0.001)$, but also that stutterers used longer response time compared to the two other groups on No Cue condition when the targets were presented in the right visual field compared to the left (see Fig. 2).

\section{The Conners Continuous Performance Test}

Two-way ANOVA with a Group (3: Con, ST and CL) $\times$ Task (5: target hits, total omissions, non-target rejections, non-target commissions and overall reaction time) yielded no significant effects.

\section{Psychophysiological measurements}

Heart rate, skin conductance and heart rate variability measures are shown in Table 4. Three one-way ANOVAs, with Group (Con, ST and CL) as independent variable and recorded values for each of the three measures HR, SCL and MSSD as dependent variables, revealed no significant differences between the groups as to psychophysiological measurements.

\section{DISCUSSION}

In this study it was hypothesized that there would be differences in attentional functions between stutterers and clutterers. This was partially confirmed. The results showed that subjects who stutter used significantly longer time on the subtest Endopos of the

Table 4. Means and standard deviations (SD) for heart rate, skin conductance and heart rate variability

\begin{tabular}{llll}
\hline & Control $(N=9)$ & Stuttering $(N=8)$ & Cluttering $(N=7)$ \\
& Mean (SD) & Mean (SD) & Mean (SD) \\
\hline Heart rate & $83.33(11.53)$ & $82.29(10.18)$ & $81.97(8.16)$ \\
Skin conductance & $14.91(5.36)$ & $13.91(3.76)$ & $9.30(3.77)$ \\
Heart rate variability & $50.22(17.23)$ & $54.36(20.21)$ & $72.91(37.33)$ \\
\hline
\end{tabular}

Note: Heart rate variability measured as MSSD (mean squared successive differences of RR-intervals). 
Posner Test of Covert Attention Shift, which measures controlled attention, compared to persons who clutter and the control group. Subjects who stutter also showed a significantly longer response time on the Posner Test of Covert Attention Shift, compared to the other groups, when the target appeared in the right visual field, and no cue was given. This means that stutterers used more time demanding internally driven shift of attention prepared in the left hemisphere than did the other groups. This may imply impaired processing of stimuli that is directed towards the right perceptual field/left hemisphere in lateralized cognitive tasks.

Stuttering seems to occur when the neurophysiological system that integrates motor, linguistic and cognitive processes, fails (9) (Curlee \& Siegel, 1997; De Nil, Kroll, Kapur, \& Houle, 1995) (24, 46 p. xvii).

One may speculate that persons who stutter become more emotionally involved when speaking, and therefore the right hemisphere becomes automatically activated $(13,15)$. Another hypothesis is that hemispheric differences point to an underlying predisposition for a rhythm dysfunction in people who stutter. These findings in brain activity have not yet resulted in any unifying theory of stuttering. This may indicate an increased activation of right hemisphere in persons who stutter, resulting in interference in the processing of stimuli directed to the left perceptual field/right cerebral hemisphere.

Subjects with cluttering showed significant shorter response time on the subtest Exopos, which measure automatic and stimuli driven shifts of attention, compared to people who stutter and controls. This may support the hypothesis that clutterers are more impulsive, unconcerned, impatient, forgetful and hectic than stutterers $(45,61)$. It is open to discussion whether the impaired scores are due to impaired attentional functions.

No significant differences between the groups were seen on the Conners Continuous Performance Test, the Dichotic Listening Test, the Stroop Color Word Test or the Wisconsin Card Sorting Test. However, interference scores on the SCWT was slightly higher in stutterers compared to clutterers and controls, which was expected based on earlier findings (9) (De Nil, Kroll, Kapur, \& Houle, 1995) $(24,46)$, although the differences did not reach a significant level. A tendency towards a higher error rate in the Wisconsin Card Sorting Test in the cluttering group was also seen. No significant between-group differences were seen in physiological activation as measured by skin conductance level and heart rate variability, lending support to earlier studies $(32,43,60)$.

These tendencies are comparable with studies indicating reduced ability to steer movements in the desired direction following stuttering (10). Metastudies have shown that people who stutter have significantly slower reaction times in starting and stopping their voice, compared to fluent speakers (De Nil, Kroll, Kapur, \& Houle, 1995) (24).

The present results support the hypothesis that stuttering may be associated with impaired focused attentional skills as seen by Posner, and that cluttering may be associated with impaired executive functions as seen by tendencies in the Wisconsin Card Sorting Test.

The study of attention and psychophysiological measurements in subjects who stutter and subjects who clutter, is a relatively new area, and although skin conductance studies in subjects with stuttering have been performed for many decades see e.g. $(32,43,47)$, the studies are inconclusive and contradictory. The implications from our study are that differences in cognitive and perceptual processing are visible in speech fluency disorders that may reflect reduced left hemisphere activation and increased right hemisphere activation associated with stuttering.

The cluttering group showed reduced response time in an automatic and stimuli-driven form of attention, indicating impulsiveness and impatience. This was shown by the Posner Test, and underlined by tendencies seen in the Wisconsin Card Sorting Test.

This study includes several new approaches to the investigation of speech fluency disorders. According to Meyers 1992, cluttering has been a neglected area in fluency research. However, the sample available within the study period was limited and the study must therefore be characterized as a pilot study. Due to the small groups, the statistical analyses should be seen as preliminary, and the results need to be confirmed in a larger sample before making firm conclusions. Further studies will be needed.

\section{REFERENCES}

1. Ainsworth $\mathrm{S}$ (editor). If your child stutters. A guide for parents. Memphis Tenn: Speech Foundation of America; 1997.

2. Andrews G, Harris M. The syndrome of stuttering. Clinics in Developmental Medicine, no. 17. London, UK: Spastics Society Medical Education and Information Unit in association with W. Heinemann Medical Books; 1964

3. Becker KP, Grundman K. Investigations on incidence and symptomatic of cluttering. Folia Phoniatr 1970; 22: 261-71.

4. Berg EA. A simple objective treatment for measuring flexibility in thinking. J Gen Psychol 1948; 39: 15-22.

5. Blood GW, Blood IM. Auditory processing and cluttering in young children. Percept Mot Skills 2000; 90: 6319 . 
6. Bloodstein O. Stuttering as an anticipatory struggle reaction. Stuttering: A symposium. J Eisenson. New York: Ed Harper and Row; 1958.

7. Bloodstein O. A handbook on stuttering. Brooklyn College of The City University of New York: National Easter Seal Society; 1987.

8. Bloodstein O. A Handbook on stuttering. London: Chapman \& Hall; 1995.

9. Braun AR, Varga M, Stager S, Schulz G, Selbie S, Maisog JM, et al. Altered patterns of cerebral activity during speech and language production in developmental stuttering; an H-sub-2 sub-1 sup 50 positron emission tomography study. Brain 1997; 120: 761-84.

10. Caruso AJ, Chodzko-Zaiko WJ, Bidinger DA, Sommers RK. Adults Who Stutter: Responses to Cognitive Stress. J Speech Hear Res 1994; 37: 746-54.

11. Conners CK. CPT. Conners' Continuous Performance Test. Canada: North Tonawanda, Multi-Health System Inc; 1995.

12. Conture EG. Stuttering, 2nd edn. New Jersey: Prentice Hall, Englewood Cliffs; 1990.

13. Cross DE, Sweet J, Bates D. Mental imagery and stuttering: Electroencephalographic and physiological characteristics. Paper presented at the American Speech-Language-Hearing Association Convention, Washington, DC; 1985.

14. Curlee RF. Stuttering and Related Disorders of Fluency, 2nd edn. New York: Thieme Medical Publishers Inc; 1999.

15. Curlee RF, Siegel G, editors. Nature and treatment of stuttering: New directions. 2nd ed. Boston: Allyn \& Bacon; 1997.

16. Dalton P, Hardcastle W. Disorders of fluency and their effects on communication, 2nd edn. London: Cole and Whurr; 1989

17. Daly D. The clutterer. In: St. Louis KO, editor. The atypical stutterer: principles and practices of rehabilitation. New York: Academic Press; 1986.

18. Daly D. Helping the clutterer: Therapy considerations. In: Myers FL, St. Louis KO, editors. Cluttering: A clinical perspective. England: Kibworth, Far Communications; 1992. p. 107-24.

19. Daly D, Burnett M. Cluttering: Assessment, Treatment Planning, and Case Study Illustration. J Fluency Disord 1996; 21: 239-48.

20. De Nil L, Kroll R, Kapur S, Houle S. A positron emission tomography study of silent and oral reading in stuttering and nonstuttering adults. J Speech Lang Hear Res 2000; 43: 1038-53.

21. DSM.IV. Diagnostic and Statistical Manual of Mental Disorders. Washington, DC: American Psychiatric Association; 1994.

22. Golden C J. Stroop Color and Word Test. A manual for clinical and experimental uses. Cat. No. 30150M. Illinois: Stoelting; 1978.

23. Green T. The production of meaningful communication, and stuttering severity. Logoped Phoniatr Vocol 1997; 22: $177-86$.

24. Guitar B. Stuttering. An Integrated Approach to Its Nature and Treatment. Vermont: The University of Vermont Burlington; 1998.

25. Hand CR, Haynes WO. Linguistic processing and reaction time differences in Stutterers and nonstutterers. J Speech Hear Res 1983; 26: 181-5.

26. Heaton RK, Curtiss G, Tuttle K. Wisconsin Card Sorting Test: computer version-2. Reasearch Editon.
Odessa FL, USA: Psychological Assessment Resources Inc; 1993.

27. Hugdahl K. Psychophysiology. The Mind-Body Perspective. Cambridge, MA: Harvard University Press; 1995.

28. Hugdahl K, Asbjørnsen A. Dikotisk lyssning til CV-stavelser. Manual. Stockholm: Psykologiförlaget AB; 1991.

29. Luchsinger R. Poltern. Erkennung, Ursachen und Behandlung. Berlin: Carl Marhold; 1963.

30. Maske-Cash W, Curlee R. Effect of utterance length and meaningfulness on the speech initiation times of children who stutter and children who do not stutter. J Speech Hear Res 1995; 38: 18-25.

31. McFarlane SC, Prons D. Neural response time of stutters and nonstutters in selected oral motor tasks. J Speech Hear Res 1978; 21: 768-78.

32. Miller SD. Multiple measures of anxiety and psychophysiologic arousal in stutters and nonstutters during nonspeech and speech tasks of increasing complexity. Dissertation Abstracts International 1993; 54(2-B): 771.

33. Mirsky AF. Disorders of attention. A Neuropsychological Perspective. In: Reid Lyon G, Krasnegor NA, editors. Attention, memory and executive function. Baltimore: Paul H. Bookes; 1996. p. 263-78.

34. Monfrais-Pfauwadel MC, Lacombe I. Attention deficits in the school aged stuttering child: constituent trait or comorbidity. Revue de Laryngologie Otologie Rhinologie 2002; 123: 291-5.

35. Moore WH. Central nervous system characteristics of stutterers. In: Curlee RF, Perkins WH, editors. Nature and treatment of stuttering: New directions. San Diego: College-Hill Press; 1984.

36. Moore WH, Haynes WO. Alpha hemispheric asymmetry and stuttering: Some support for a segmentation dysfunction hypothesis. J Speech Hear Res 1980; 23: 229-47.

37. Murphy AT, Fitzimons RM. Stuttering and Personality Dynamics. New York: The Ronald Press Company; 1960.

38. Myers FL, St. Louis KO. Cluttering: A Clinical Perspective. Leicester: Far Communications Ltd; 1992.

39. Myers FL, St. Louis KO. Cluttering: Issues and Controversies. In: Myers FL, St. Louis KO, editors. Cluttering: A Clinical Perspective. Leicester: Far communications Ltd; 1992.

40. Myers FL. Cluttering: A Synergistic Framework. In: Myers FL, St. Louis KO, editors. Cluttering: A clinical perspective. Leicester: Far communications Ltd; 1992.

41. Myers FL. Cluttering: A matter of perspective. J Fluency Disord 1996; 213-4: 175-86.

42. Myers FL. Annotations of Research and Clinical Perspectives on Cluttering Since 1964. Fluency Disorders 1996; 21: 187-200.

43. Peters HFM, Hulstijn W. Stuttering and Anxiety: The difference between stutterers and nonstutterers in verbal apprehension and physiologic arousal during the anticipation of speech and non-speech tasks. J Fluency Disord 1984; 9: 67-84.

44. Posner MI. Orienting of attention. Q J Exp Psychol 1980; 32: 3-25.

45. Preus A. Stamming og løpsk tale. 2.utgave. Oslo: Universitetsforlaget; 1987.

46. Rustin L, Purser H, Rowley D. Progress in the treatment of fluency disorders. London, New York, Philadelphia: Taylor and Francis; 1987. 
47. Shearn D, Bergman E, Hill K, Abel A, Hinds L. Blushing as a function of audience size. Psychophysiology 1992; 29: 431-6.

48. Sheehan JG. Stuttering. Research and therapy. New York: Harper \& Row; 1970.

49. Starkweather CW, Gottwald SR, Halfond MH. Stuttering prevention: A clinical method. New Jersey: Englewood Cliffs Prentice Hall; 1990.

50. Starkweather CW, Franklin S, Lacombe I. Vocal and finger reaction times in stutterers and nonstutterers: differences and correlations. J Speech Hear Res 2002; 27: 193-6.

51. St. Louis KO, Hinzman A, Hull F. Studies of cluttering disfluency and language measures in young possible clutterers and stutterers. J Fluency Disord 1985; 10: $151-272$.

52. St. Louis KO. On Defining Cluttering. In: Myers FL, St. Louis KO, editors. Cluttering: A Clinical Perspective. Leicester: Far communications Ltd; 1992. p. 37-54.

53. Stroop JR. Studies of interference in serial verbal reactions. J Exp Psychol 1935; 18: 643-62.

54. Teigland A. Løpsktalende ungdomsskoleelever i dialog med normaltalende. Hovedoppgave UiO. [Master paper, University of Oslo, Norway]. 1994.
55. Thayer JF, Friedman BH, Borkovec TD, Johnsen BH, Molina S. Phasic heart period reactions to cued threat and nonthreat stimuli in generalized anxiety disorder. Psychophysiology 2000; 37: 361-8.

56. Tranel D, Anderson SW, Benton A. Development of the concept of "executive functions" and its relationship to the frontal lobes. In: Boller IF, Grafman J, editors. Atypical cognitive deficits in developmental disorders; implications for brain function. Hillsdale, NJ: Erlbaum Associates, 1994.

57. Van Riper C. The nature of stuttering. Englewood Cliffs, NJ: Prentice Hall; 1982.

58. Watson BC, Alfonso PJ. Physiological bases of acoustic LRT in nonstutters, mild stutters, and severe stutters. J Speech Hear Res 1987; 30: 434-47.

59. Weber C, Smith A. Autonomic correlates of stuttering and speech assessed in a range of experimental tasks. $\mathbf{J}$ Speech Hear Res 1990; 33: 690-706.

60. Webster WG. Evidence in bimanual finger-tapping of an attentional component to stuttering. Behav Brain Res 1990; 37: 193-6.

61. Weiss DA. Cluttering. Englewood Cliffs, NJ: Prentice Hall; 1964.

62. Yari E, Ambrose N, Cox N. Genetics of stuttering: A critical review. J Speech Hear Res 1996; 36: 521-8. 
Copyright of Logopedics Phoniatrics Vocology is the property of Taylor \& Francis Ltd and its content may not be copied or emailed to multiple sites or posted to a listserv without the copyright holder's express written permission. However, users may print, download, or email articles for individual use. 